\title{
PERBEDAAN BOUNDING ATTACHMENT PADA IBU NIFAS YANG MEMBERIKAN INISIASI MENYUSU DINI DENGAN YANG TIDAK MEMBERIKAN INISIASI MENYUSU DINI (Studi Kasus di RSUD Sidoarjo 2013)
}

\section{Lestari Okta Ambarwati ${ }^{1}$, Sumiati ${ }^{2}$}

1. Mahasiswa Program Studi D III Kebidanan Universitas PGRI Adi Buana Surabaya 2. Tenaga Pengajar Program Studi D III Kebidanan Universitas PGRI Adi Buana Surabaya

\section{ABSTRAK}

Bounding Attachment terjadi pada kala IV, dimana diadakan kontak antara ibu dan bayi dan berada pada ikatan kasih. Tujuan dari penelitian ini adalah untuk mengetahui bagaimana perbedaan bounding attachment pada ibu nifas yang memberikan inisiasi menyusu dini dengan yang tidak memberikan inisiasi menyusu dini di RSUD Sidoarjo Kabupaten Sidoarjo.

Metode dalam penelitian ini adalah deskriptif dengan desain penelitian observasional menggunakan rancangan penelitian cohort. Sampel yang digunakan adalah ibu bersalin yang memenuhi kriteria inklusi dan eksklusi sebanyak 30 ibu nifas. Teknik sampling yang digunakan adalah Puposive Sampling. Pengumpulan data diperoleh pada tanggal 14 Juni - 14 Juli 2013, dengan cara mengisi lembar checklist melalui observasi langsung pada ibu nifas. Hasil penelitian menunjukkan dari 30 ibu nifas yang menjadi responden, 15 ibu ( $50 \%$ ) berhasil dilakukan IMD, sedangkan yang 50\% tidak diberikan IMD karena kondisi ibu dan bayi yang tidak memungkinkan. Hasil penelitian diperoleh $50 \%$ ibu yang memberi perlakuan IMD : 47\% mempunyai interaksi positif dan 3\% mempunyai interaksi negatif, sedangkan $50 \%$ ibu yang tidak memberikan perlakuan IMD, 43\% mempunyai interaksi negatif dan 7\% mempunyai interaksi positif. Berdasarkan hasil perhitungan tersebut dapat disimpulkan bahwa adaperbedaan bounding attachment pada ibu nifas yang memberikan inisiasi menyusu dini dengan yang tidak memberikan inisiasi menyusu dini.

Saran yang dapat diberikan kepada petugas kesehatan hendaknya patuh dan disiplin dalam melaksanakan kegiatan IMD dimana selain bermanfaat meningkatkan bounding attachment juga untuk meningkatkan program pemerintah untuk pemberian ASI Esklusif.

Kata kunci : Inisiasi Menyusu Dini, Bounding Attachment.

\section{PENDAHULUAN}

Saat ini usaha untuk meningkatkan penggunaan ASI telah menjadi tujuan global. Setiap tahun pada tanggal 1-7 Agustus adalah pekan ASI sedunia. Pada saat itu penggunaan ASI dievaluasi. Di Indonesia walaupun sejak tahun 1992 telah dilakukan kegiatan Rumah Sakit Sayang Bayi kemudian ditambah lagi dengan kegiatan Rumah Sakit Sayang lbu sejak 1999, situasi menyusuimasih belum seperti yang di harapkan (Prawirohardjo, 2008).Inisiasi Menyusui Dini (IMD) adalah proses pertama kali bayi menyusu pada ibu, proses ini dilakukan segerasetelah bayi dilahirkan, bayi diletakkan di dada atau di perut atas ibu selama paling sedikit satu jam untuk memberikan kesempatan pada bayi untuk mencari dan menemukan puting ibunya (Prawirohardjo, 2008).
Manfaat Inisiasi Menyusu dini bagi bayi adalah mambantu stabilisasi pernapasan, mengendalikan suhu tubuh lebih baik dibandingkan dengan inkubator, menjaga kolonisasi kuman yang aman untuk bayi dan mencegah infeksi nosokomial. Kadar bilirubin bayi juga lebih cepat normal karena pengeluaran mekonium lebih cepat sehingga dapat menurunkan insiden ikterus pada bayi baru lahir. Kontak kulit dengan kulit juga membuat bayi lebih tenang sehingga didapat pola tidur yang lebih baik. Bagi ibu dapat memperbesar peluang ibu untuk memantapkan dan melanjutkan kegiatan menyusui selama masa bayi, dan secara psikologis meningkatkan ikatan batin antara ibu dan bayi dalam bentuk kasih sayang dan belaian (Bounding Attachment), dan dapat mengurangi stres setelah melahirkan (Prawirohardjo, 2008). 
Data penunjang menurut Riskesdes 2010, dimana cakupan pemberian ASI saja pada bayi usia 0 bulan $39,8 \%$, usia $0-1$ bulan $32,5 \%$, usia $0-2$ bulan $30,7 \%$, usia 0 3 bulan $25,2 \%$, usia $0-4$ bulan $26,3 \%$, usia 0-5 bulan $15,3 \%$, dan untuk pemberian ASI Esklusif sebesar 27,2\%. Data ini masih jauh dari target Indonesia sebesar $80 \%$, sedangkan cakupan inisiasi menyusu dini (IMD) sebesar $27,5 \%$. Ada yang menarik dari cakupan data tersebut, dimana cakupan persalinan yang ditolong oleh Nakes (tenaga kesehatan) sebesar $84.7 \%$, tetapi bayi yang mulai disusui kurang dari 1 jam atau inisiasi menyusu dini(IMD) sebesar 29,3\% dan yang mendapat makanan dan minuman prelakteal masih tinggi yaitu $43,6 \%$. Peran tenaga kesehatan sangat berpengaruh untuk meningkatkan program inisiasi menyusu dini dan ASI Esklusif mengingat cakupan pemberian inisiasi menyusu dini(IMD) masih rendah yaitu sekitar $29,3 \%$ dan pemberian ASI Esklusif 27,2\% (Yekti Wido, 2011).

Upaya meninggkatkan pemberian ASI Eksklusif telah dilakukan salah satu programnya itu menyusui pada satu jam pertama kehidupan. Sebanyak 22\% kematian bayi di bawah usia 28 hari dapat dicegah jika bayi diberi kesempatan dalam satu jam pertama dengan dibiarkan kontak kulit ke kulit ibu (dr.Karen Edmon, 2006).

Berdasarkan keterangan diatas dapat di simpulkan bahwa pelaksanaan IMD di Indonesia masih tergolong sedikit, diharapkan pemberian sosialisasi program IMD dapat meningkatkan program ini melihat berbagai keuntungan untuk ibu dan bayi salah satunya yaitu ikatan batin dalam bentuk kasih sayang "Bounding Attachment"'

Berdasarkan paparan di atas timbul pertanyaan tentang Pengaruh IMD dengan adanya Bounding Attachment, sehingga penulis tertarik untuk meneliti Perbedaan Bounding Attachment Pada Ibu Nifas Yang Memberikan Inisiaisi Menyusu Dini (IMD) dengan lbu Nifas Yang Tidak Memberikan Inisiasi Menyusu Dini(IMD).

\section{Rumusan Masalah Dalam Penelitian Ini} adalah :

Adakah perbedaan antara bounding attachment pada ibu nifas yang memberikan inisiaisi menyusu dini (IMD) dengan yang tidak memberikan inisiasi menyusu dini (IMD) di RSUD Sidoarjo.

\section{Tujuan Penelitian}

Tujuan Umum Penelitian adalah :

Mempelajari perbedaan bounding attachmentpada ibu nifas yang memberikan IMD dengan ibu nifas yang tidak memberikan IMD di RSUD Sidoarjo.

\section{Tujuan Khusus}

1. Mengidentifikasi perlakuan IMD di RSUD Sidoarjo.

2. Mengedintifikasi bounding attachment di RSUD Sidoarjo.

3. Menganalisis perbedaan bounding attachment pada ibu nifas yang memeberikan IMD dengan ibu nifas yang tidak memberikan IMD di RSUD Sidoarjo.

\section{BAHAN DAN METODE}

Dalam penelitian ini menggunakan desain observasional dengan melakukan pengamatan atas perilaku objek dan bersifat partisipatif dan nonpartisipatif. Dalam desain observasional dan wawancaraini menggunakan rancangan penelitian Cohort yang merupakan rancangan penelitian yang di gunakan untuk mempelajari dinamika korelasi antara faktor resiko dengan efek melalui pendekatan longitudinal kedepan atau prospektif, dengan mengelompokkan atau mengklasifikasikan kelompok terpapar dengan tidak terpapar, untuk kemudian diamati sampai waktu tertentu untuk melihat ada tidaknya fenomena (Notoatmodjo, 2010). Penelitian ini mengamati tentang perbedaan ibu nifas yang memberikan inisiasi menyusu dini dan tidak memberikan inisiasi menyusu dini dengan adanya bounding attachment dan peneliti melakukan pengukuran atau pengamatan terhadap bagaimana bayi-bayi yang diberi perlakuan inisiasi menyusu dini yang diukur dan diamati bagaimana bounding attachment antara ibu dan bayinya.

Populasi dalam penelitian ini adalah ibu bersalin di RSUD Sidoarjo yang memenuhi kriteria inklusi dan eksklusi sejak bulan juni - sampai bulan juli 2013

Besar sampel 30 orang dibagi menjadi 2 yaitu 15 ibu nifas yang memberikan pemberian inisiasi menyusu 
dini dan 15 ibu nifas yang tidak memberikan inisiasi menyusu dini.

\section{Teknik Sampling :}

Metode pengambilan sample yang digunakan adalahpurposive samplingyaitu pengambilan sample yang didasarkan pada suatu pertimbangan tertentu yang dibuat oleh peneliti sendiri, berdasarkan ciri atau sifat-sifat populasi yang sudah diketahui cirinya (Notoadmodjo,2010). Ciri yang dimaksud yaitu ibu post partum yang bayinya diberi perlakuan IMD, bayi yang aterm dan ibu dengan persalinan fisiologis dan patologis. Teknik sampling ini dilakukan oleh peneliti setelah ibu melahirkan dimana ibu telah memenuhi ciri-ciri tersebut.

\section{Hasil dan Pembahasan}

Pada bab ini akan diuraikan tentang hasil penelitian sesuai dengan rumusan masalah dan tujuan penelitian yang ada pada bab pendahuluan. Secara jelas uraian hasil penelitian disajikan mengenai hasil pengumpulan data dari lembar observasi yang dilaksanakan mulai tanggal 14 juni sampai dengan 14 Juli 2013 di RSUD Sidoarjo sebanyak 30 responden. Hasil penelitian ini meliputi perbedaan Bounding Attachmentpada ibu nifas yang memberikan inisiasi menyusu dini dengan yang tidak memberikan inisiasi menyusu dini. Karakteristik umum responden meliputi usia, pendidikan, pekerjaan serta jumlah persalinan atau paritas. Data khusus meliputi ibu bersalin yang dilakukan tindakan Inisiasi Menyusu Dini dengan interaksi bounding attachment yang positif atau negatif.

Tabel 1. Distribusi frekuensi ibu nifas berdasarkan usia di wilayah kerja RSUD Sidoarjo pada bulan Juni - Juli 2013

Sumber : Data primer yang diolah (2013)

Tabel 1. menunjukkan dari 30 ibu diperoleh $67 \%$ berusia $20-35$ tahundan $3 \%$ berusia < 20 tahun.
Tabel2.Distribusi Frekuensi ibu nifas Berdasarkan Tingkat Pendidikan di RSUD Sidoarjo pada bulan Juni - Juli

\begin{tabular}{|c|c|c|}
\hline Usia & $\begin{array}{c}\text { Frekuensi } \\
(\mathbf{F})\end{array}$ & $\begin{array}{c}\text { Persentase } \\
(\mathbf{P})\end{array}$ \\
\hline$<\mathbf{2 0}$ Tahun & 1 & $3 \%$ \\
\hline $\begin{array}{c}\mathbf{2 0}-\mathbf{3 5} \\
\text { Tahun }\end{array}$ & 20 & $67 \%$ \\
\hline$>\mathbf{3 5}$ Tahun & 9 & $30 \%$ \\
\hline Total & $\mathbf{3 0}$ & $\mathbf{1 0 0} \%$ \\
\hline
\end{tabular}

2013.

\begin{tabular}{|c|c|c|}
\hline $\begin{array}{c}\text { Tingkat } \\
\text { Pendidikan }\end{array}$ & $\begin{array}{c}\text { Frekuensi } \\
\text { (F) }\end{array}$ & $\begin{array}{c}\text { Persentase } \\
\text { (P) }\end{array}$ \\
\hline Tinggi & 1 & $3 \%$ \\
\hline Menengah & 23 & $77 \%$ \\
\hline Dasar & 6 & $20 \%$ \\
\hline Total & $\mathbf{3 0}$ & $\mathbf{1 0 0} \%$ \\
\hline \multicolumn{2}{|r|}{ Sumber : Data primer yang diolah (2013) }
\end{tabular}

Tabel 2 menunjukkan dari 30 ibu diperoleh $77 \%$ memiliki tingkat pendidikan Menengah, 3\% memiliki tingkat pendidikan tinggi.

Tabel 3. Distribusi Frekuensi ibu nifas Berdasarkan Pekerjaan di wilayah kerja RSUD Sidoarjo pada bulan Juni - Juli 2013

\begin{tabular}{|c|c|c|}
\hline Pekerjaan & $\begin{array}{c}\text { Frekuensi } \\
\text { (F) }\end{array}$ & $\begin{array}{c}\text { Persentase } \\
\text { (P) }\end{array}$ \\
\hline Bekerja & 7 & $23 \%$ \\
\hline Tidak Bekerja & 23 & $77 \%$ \\
\hline Total & $\mathbf{3 0}$ & $\mathbf{1 0 0} \%$ \\
\hline
\end{tabular}

Sumber : Data primer yang diolah (2013)

Tabel 3. menunjukkan dari 30 ibu diperoleh $77 \%$ bekerja dan $23 \%$ tidak bekerja.

Tabel 4. Distribusi frekuensi ibu nifas Berdasarkan Jumlah Anak di wilayah kerja di RSUD Sidoarjo pada bulan Juni - Juli 2013.

\begin{tabular}{|c|c|c|}
\hline Jumlah Anak & $\begin{array}{c}\text { Frekuensi } \\
(\mathbf{F})\end{array}$ & $\begin{array}{c}\text { Persentase } \\
(\mathbf{P})\end{array}$ \\
\hline $\mathbf{1 - 2}$ & 19 & $63 \%$ \\
\hline $\mathbf{3 - 4}$ & 8 & $27 \%$ \\
\hline $\mathbf{4}$ & 3 & $10 \%$ \\
\hline Total & $\mathbf{3 0}$ & $\mathbf{1 0 0} \%$ \\
\hline
\end{tabular}

Sumber : Data primer yang diolah ( 2013) 
Tabel 4. menunjukkan dari 30 ibu diperoleh $63 \%$ mempunyai anak 1 - 2 anak dan 10 $\%$ mempunyai anak $>4$ anak.

Tabel 5. Distribusi frekuensi ibu nifas berdasarkan Pelaksanaan IMD di RSUD Sidoarjo pada bulan Juni - Juli 2013.

\begin{tabular}{|c|c|c|}
\hline $\begin{array}{c}\text { Inisiasi } \\
\text { Menyusu } \\
\text { Dini }\end{array}$ & $\begin{array}{l}\text { Frekuensi } \\
\text { (F) }\end{array}$ & $\begin{array}{c}\text { Persentase } \\
\text { (P) }\end{array}$ \\
\hline $\begin{array}{l}\text { Diberikan } \\
\text { IMD }\end{array}$ & 15 & $50 \%$ \\
\hline $\begin{array}{c}\text { Tidak } \\
\text { Diberikan } \\
\text { IMD }\end{array}$ & 15 & $50 \%$ \\
\hline Total & 30 & $100 \%$ \\
\hline
\end{tabular}

Sumber : Data primer yang diolah (2013) Tabel 5. menunjukkan dari $50 \%$ ibu diberi perlakuan IMD dan $50 \%$ tidak diberi perlakuan IMD.

Tabel 6. Distribusi frekuensi ibu nifas yang memberikan inisiasi menyusu dini berdasarkan Interaksi bounding attachment di wilayah kerja RSUD Sidoarjo pada bulan Juni - Juli 2013.

\begin{tabular}{|c|c|c|}
\hline Attachment & (F) & (P) \\
\hline Positif (+) & 14 & $47 \%$ \\
\hline Negatif (-) & 1 & $3 \%$ \\
\hline Total & $\mathbf{1 5}$ & $\mathbf{5 0} \%$ \\
\hline
\end{tabular}

Sumber : Data primer yang diolah (2013)

Tabel 6. menunjukkan dari 15 ibu diperoleh $47 \%$ mempunyai interaksipositif dan $3 \%$ mempunyai interaksi negatif.

Tabel 7. Distribusi frekuensi ibu nifas yang tidak memberikan inisiasi menyusu dini berdasarkan Interaksi bounding attachment di wilayah kerja RSUD Sidoarjo pada bulan Juni - Juli 2013.

\begin{tabular}{|c|c|c|}
\hline $\begin{array}{c}\text { Bounding } \\
\text { Attachment }\end{array}$ & $\begin{array}{c}\text { Frekuensi } \\
\text { (F) }\end{array}$ & $\begin{array}{c}\text { Persentase } \\
\text { (P) }\end{array}$ \\
\hline Positif (+) & 2 & $7 \%$ \\
\hline Negatif (-) & 13 & $43 \%$ \\
\hline Total & $\mathbf{1 5}$ & $\mathbf{5 0} \%$ \\
\hline
\end{tabular}

Sumber : Data primer yang diolah (2013)

Tabel 7. menunjukkan dari 15 ibu diperoleh $7 \%$ mempunyai interaksipositif dan $43 \%$ mempunyai interaksi negatif.

\section{\begin{tabular}{|l|l|l|}
\hline Bounding & Frekuensi & Persentase \\
\hline
\end{tabular}}

Tabel 8. Perbedaan bounding attachment pada ibu nifas yang memberikan inisiasi menyusu dini dengan yang tidak memberikan inisiasi menyusu dini.di wilayah kerja di RSUD Sidoarjo pada bulan Juni - Juli 2013.

\begin{tabular}{|c|c|c|c|c|c|c|}
\hline \multirow{2}{*}{ Inisiasi Menyusu Dini } & \multicolumn{2}{|c|}{$\begin{array}{c}\text { BOUNDING } \\
\text { Interaksi }\end{array}$} & \multicolumn{2}{c|}{$\begin{array}{c}\text { ATTACHMENT } \\
(+)\end{array}$} & \multicolumn{2}{c|}{ Total } \\
\cline { 2 - 7 } & F & P & F & P & F & P \\
\hline Diberikan IMD & 14 & $47 \%$ & 1 & $3 \%$ & 15 & $50 \%$ \\
Tidak diberikan IMD & 2 & $7 \%$ & 13 & $43 \%$ & 15 & $50 \%$ \\
\hline Total & 16 & $50 \%$ & 14 & $50 \%$ & 30 & $100 \%$ \\
\hline
\end{tabular}

Sumber :Data primer yang diolah (2013)

Tabel 8. menunjukkan dari 30 ibu diperoleh $50 \%$ ibu yang memberi perlakuan IMD dengan $47 \%$ mempunyai interaksi positif dan 3\% mempunyai interaksi negatif, sedangkan $50 \%$ ibu yang tidak memberikan

perlakuan IMD dengan 43\% mempunyai interaksi negatif dan 7\% mempunyai interaksi positif.

\section{Analisis Deskriptif}


Hasil observasi dianalis dengan rumus persentase $P=F / N$ dan wawancara untuk memperkuat hasil observasi. Kesimpulan dari 30 responden diperoleh $50 \%$ ibu yang memberi perlakuan IMD dengan 47\% mempunyai interaksi positif dan 3\% mempunyai interaksi negatif, sedangkan $50 \%$ ibu yang tidak memberikan perlakuan IMD dengan $43 \%$ mempunyai interaksi negatif dan 7\% mempunyai interaksi positif pada ibu nifas di RSUD Sidoarjo.

\section{Identifikasi Inisiasi Menyusu Dini}

Hasil penelitian didapatkan dari ibu nifas yang memberikan perlakuan inisiasi menyusu dini sebesar $100 \%$ bayi berhasil melakukan Inisiasi Menyusu Dini. Keberhasilan ini dapat dilihat dari bayi baru lahir yang dapat menemukan puting susu ibu dengan kurun waktu $\leq 1$ jam atau bayi dapat melakukan langkah-langkah inisiasi menyusu dini dengan benar. Inisiasi Menyusu Dini ini dapat berhasil karena dipengaruhi oleh beberapa faktor, antara lain kesehatan ibu, kesehatan bayi, rasa percaya diri ibu yang timbul dari adanya dukungan baik dari suami, keluarga maupun dari bidan.

Berdasarkan tingkat pendidikan didapatkan $77 \%$ memiliki tingkat pendidikan menengah, disini berhubungan dengan tingkat pengetahuan ibu yang dirasa cukup, hal ini ibu akan lebih kooperatif dalam segala tindakan yang disarankan oleh tenaga kesehatan dalam pemberian informasi tentang cara serta proses IMD.

Faktor-faktor yang mempengaruhi keberhasilan IMD tersebut sesuai dengan teori menurut Bianccuzzo (1999) adalah sosial budaya, psikologi dan biologis ibu sendiri. Sementara menurut Arbon dan Byrne (2001) faktor-faktor yang mempengaruhi ibu untuk inisiasi menyusu dini antara lain yaitu yang pertama faktor psikologi, dimana status psikologi mendasari ibu dan pendukungnya untuk keberhasilan menyusui, termasuk percaya diri ibu dan komitmen untuk menyusui. Jenis dari dukungan termasuk memberi informasi, emosi dan memberi pertolongan. Dukungan emosi termasuk memberi pengertian, membesarkan hati dan menyayangi. Dukungan pertolongan termasuk memberi pertolongan fisik untuk dapat menyusui bayinya. Pemberi dukungan termasuk keluarga, suami, tenaga kesehatan dan lingkungan budaya. Kedua yaitu faktor dukungan tenaga kesehatan dimana dukungan yang diberikan oleh tenaga kesehatan dapat membangkitkan rasa percaya diri ibu untuk membuat keputusan menyusui bayinya, kontak awal-bayi, petunjuk-petunjuk menyusui, tipe bantuan yang dibutuhkan oleh ibu merupakan dukungan tenaga kesehatan untuk menyukseskan kelangsungan pemberian ASI eksklusif. Ketiga yaitu faktor biomedik dimana faktor biomedik terdiri dari jumlah kelahiran, kesehatan bayi dan kesehatan ibu (selama hamil, melahirkan dan setelah melahirkan). Kesiapan fisik yang mendukung ibu dalam melakukan inisiasi menyusui dini, salah satunya adalah kondisi payudara dan puting susu yang sehat dan baik.

\section{Identifikasi Bounding attachment}

Hasil penelitian didapatkan ibu nifas yang memberikan perlakuan inisiasi menyusu dini $47 \%$ yang mempunyai interaksi positif pada bounding attachment dan $3 \%$ yang mempunyai interaksi negatif, sedangkan ibu nifas yang tidak memberikan perlakuan inisiasi menyusu dini $7 \%$ mempunyai interaksi positif pada bounding attachment dan $43 \%$ yang mempunyai interaksi negatif. Interaksi positif dan negatif ini dapat dilihat dari hasil pengamatan langsung yang dapat diketahui dari interaksi ibu terhadap bayinya. Tindakan ibu digolongkan menjadi tiga yaitu memandang, berkata dan melakukan sesuatu. Dari tindakan ibu memandang, aspek yang dinilai yaitu ibu terlihat sangat gembira, bahagia, tersenyum dan antusias dengan kehadiran bayinya. Tindakan ibu berkata, aspek yang dinilai yaitu ibu berbicara langsung, menggunakan nama bayinya, memperlihatkan reaksi, memuji bayinya, serta membuat sebutan bagi bayi. Sedangkan tindakan melakukan sesuatu, aspek yang dinilai antara lain yaitu mengulurkan tangan ingin memegang bayinya, memeriksa bayinya, membuat kontak mata dengan bayinya dan mencium. Dari aspek yang dinilai dikatakan mempunyai interaksi positif jika skor yang dijumlahkan yaitu 10-12. Interaksi positif pada bounding attachment ini dapat tercipta karena dipengaruhi oleh beberapa faktor yaitu adanya dukungan dari suami, keluarga dan tenaga kesehatan, keterampilan ibu yang berusaha mengajak bicara pada bayinya, rasa senang akan kehadiran bayinya serta kecocokan jenis kelamin pada bayinya.

Hal ini juga diperkuat oleh teori yaitu Menurut Mercer (1996), prakondisi yang mempengaruhi ikatan antara lain :Kesehatan emosional orang tua, sistem dukungan sosial 
yang meliputi pasangan hidup, teman, dan keluarga, suatu tingkat keterampilan dalam berkomunikasi dan dalam memberi asuhan yang kompeten,kedekatan orang tua dengan bayi, kecocokan orang tua - bayi (termasuk keadaan,temperamen, dan jenis kelamin).

Sedangkan interaksi negatif yang ditimbulkan dapat dilihat dari jumlah skor pada lembar observasi yang diketahui dari interaksi ibu terhadap bayinya yaitu 3-6. Dimana interaksi negatif yang terjadi pada ibu nifas terjadi karena adanya ketidak cocokan antara ibu dan bayi, dimana ibu tidak menginginkan jenis kelamin anaknya selain itu ibu merasa tidak ada dukungan dari suaminya. Hal ini juga diperkuat oleh teori yaitu Menurut Mercer (1996) yaitu hambatan bounding attachment antara lain kurangnya support system atau kurangnya dukungan dari suami ataupun keluarga, ibu dengan resiko, bayi dengan resiko, kehadiran bayi yang tidak diinginkan, serta kesehatan emosional orang tua yang tidak stabil.

Kecocokan orang tua dan bayi serta support system dari keluarga terutama suami sangat mempengaruhi adanya interaksi bounding attachment ini, dimana dengan adanya kecocokan dan support system dari keluarga ibu akan merasa lebih percaya diri dalam merawat bayinya dan komunikatif kepada bayinya sehingga terciptalah tinteraksi positif bounding attachment. Untuk itulah keluarga mempunyai peranan penting dalam memberikan dukungan kepada ibu untuk menumbuhkan rasa percaya dirinya sehingga ketidak cocokan antara ibu dan bayi dapat diminimalisir sehingga tidak akan terjadi interaksi negatif pada bounding attachment antara ibu dan bayinya, selain itu tenaga kesehatan mempunyai peranan penting dimana tugas dari tenaga kesehatan itu sendiri sebagai fasilitator serta memberikan dukungan emosional kepada ibu agar ibu lebih percaya diri dalam merawat bayinya sendiri sehingga terciptalah interksi positif pada bounding attachment.

\section{Analisis Perbedaan bounding attachment pada ibu nifas yang memberikan inisiasi menyusu dini dengan yang tidak memberikan inisiasi menyusu dini.}

Hasil penelitian menunjukkan ada perbedaan bounding attachment pada ibu nifas yang memberikan inisiasi menyusu dini dengan yang tidak memberikan inisiasi menyusu dini. Apabila inisiasi menyusu dini yang dilakukan berhasil maka bounding attachment cenderung mempunyai interaksi positif.Hasil penelitian ini menunjukkan ada perbedaan bounding attachment pada ibu nifas yang memberikan inisiasi menyusu dini dengan yang tidak memberikan inisiasi menyusu dini, karena ibu yang memberikan inisiasi menyusu dini akan terjadi kontak skin to skin antara ibu dan bayi sehingga bayi akan merasa hangat, ibu juga akan melakukan kontak mata pada bayinya, maka ibu dan bayi akan terjalin ikatan emosional yang akan menimbulkan interaksi positif pada bounding attachment. Dimana dalam proses ini juga dipengaruhi oleh beberapa faktor, antara lain: kesehatan emosional orang tua, sistem dukungan sosial, suatu tingkat keterampilan dalam berkomunikasi, kedekatan orang tua pada bayi serta kecocokan orang tua pada bayi termasuk kecocokan keadaan maupun jenis kelamin anaknya. Sedangkan ibu yang tidak memberikan inisiasi menyusu dini tidak akan terjadi proses - proses tersebut.

Mengingat adanya perbedaan bounding attachment pada ibu nifas yang memberikan inisiasi menyusu dini dengan yang tidak memberikan inisiasi menyusu dini, diharapkan seluruh bayi pada 1 jam pertama setelah lahir mendapatkan inisiasi menyusu dini agar bisa terjalin interaksi posotif pada bounding attachment, disini kedisiplinan tenaga kesehatan berperan penting dalam pemberian inisiasi menyusu dini, karena masih banyak bayi yang tidak mendapatkan inisiasi menyusu dini dalam satu jam pertama waktu dia lahir. Tidak ada alasan untuk tidak memberikan inisiasi menyusu dini kecuali karena keadaan ibu dan bayi yang tidak memungkinkan untuk dilakukan inisiasi menyusu dini. Untuk itulah diharapkan agar tenaga kesehatan selalu disiplin dalam memfasilitasi ibu dalam pemberian inisiasi menyusu dini. Untuk meminimalisir terjadinya interaksi negatif bounding attachment antara ibu dan bayinya, diperlukan kedisiplinan dari tenaga kesehatan untuk memberikan inisiasi menyusu dini serta dukungan dari keluarga.

\section{Simpulan dan Saran}

Simpulan dalam penelitian ini adalah : 
Ada perbedaan bounding attachment pada ibu nifas yang memberikan inisiasi menyusu dini dengan ibu nifas yang tidak memberikan inisiasi menyusu dini, dengan penjelasan sebagai berikut:

1. Proses inisiasi menyusu dini di RSUD Sidoarjo selalu diberikan jika kondisi janin dan ibu baik.

2. Bounding attachment pada ibu yang memberikan inisiasi menyusu dini dengan yang tidak memberikan inisiasi menyusu dini mempunyai interaksi yang berbeda.

3.Ada perbedaan bounding attachment antara ibu nifas yang memberikan inisiasi menyusu dini dengan yang tidak memberikan inisiasi menyusu dini, dengan hasil dari 15 ibu atau sebesar $50 \%$ yang memberiakan perlakuan IMD $47 \%$ mempunyai interaksi positif dan $3 \%$ mempunyai interaksi negatif, sedangkan dari 15 ibu atau sebesar $50 \%$ yang tidak memberikan perlakuan IMD $43 \%$ mempunyai interaksi negatif dan $7 \%$ mempunyai interaksi positif pada ibu nifas di RSUD Sidoarjo.

\section{Saran}

\section{Bagi Tempat Penelitian}

Diharapkan RSUD Sidoarjo dapat mempertimbangkan kebijakan dalam pelaksanaan inisiasi menyusu dini dalam setiap pertolongan persalinan dan diharapkan dapat terus menggalakkan program IMD untuk ikut serta dalam meningkatkan cakupan ASI Eksklusif sesuai target indikator Indonesia sehat yaitu $80 \%$.

\section{DAFTAR PUSTAKA}

Roesli, Utami (2012). Panduan Inisiasi Menyusu Dini Plus Asi Eksklusif. Jakarta: Pustaka Bunda.

Prawirohardjo, Sarwono (2008). Ilmu Kebidanan. PT Bina Pustaka Sarwono Prawirohardjo. Jakarta: 369

Retno, Setyo dan Sri Handayani (2011). Asuhan Kebidanan Ibu Masa Nifas. Yogyakarta: Gosyen Publishing.

Khasanah, Nur (2011). Asi Atau Susu Formula Ya?. Yogyakarta: FlashBooks.

Saleha, Siti (2009). Asuhan Kebidanan Pada Masa Nifas. Jakarta: Salemba Medika.

Suherni, dkk (2009). Perawatan Masa Nifas. Jakarta: Salemba Medika.

http://aimi-asi.org/wp-content/uploads/ 2013/01/14-kepkadinkes no 4352008 IMD.pdf. Diakses tanggal 1 Maret 2013.

Marmi (2012). Asuhan Kebidanan pada Masa Nifas "Perperium Care". Yogyakarta: Pustaka Pelajar.

Anggraeni, Silvia (2009). Hubungan Antara Inisiasi Menyusu Dini Dengan Bounding Attachment Pada Ibu Nifas Di BPS Barti Desa Rejosari Kecamatan Bantur Kabupaten Malang.KTI. Malang: STIKES Widyagama Husada Malang : 34-38.

http://superbidanhapsariwordpress.com/2009/12/14/makalah-askeb-2-96E29680969Cimddan-bounding-attachment96E296809690/. Diakses tanggal 9 Maret 2013.

http://www.persagi.org/./ Diakses tanggal 08 Maret 2013.

Notoatmodjo, Soekidjo (2010). Metodologi Penelitian Kesehatan. Jakarta: Rineka Cipta.

Hidayat, Aziz Alimul (2011). Metode Penelititian Kesehatan Paradigma Kuantitatif. Surabaya: Health Books Publishing. 